\title{
INFLUÊNCIA DE LÍQUIDOS IÔNICOS NO TRATAMENTO DA PALHA DE MILHO PARA A PRODUÇÃO DE BIOETANOL
}

\author{
A. A. MORNDIM-GIANNETTII ${ }^{1, *}$, P. R. CAMPOS $^{1}$, A. P. VIANA ${ }^{1}$, R. P. T. MARTINEZ ${ }^{1}$, \\ M. DAMINATO ${ }^{1}$, R. C. SILVA ${ }^{1}$ e M. A. SANTORO ${ }^{1}$ \\ ${ }^{1}$ Centro Universitário FEI, Departamento de Engenharia Química \\ *E-mail: preamorandim@fei.edu.br
}

\begin{abstract}
RESUMO: Este estudo propôs verificar a eficiência do tratamento da palha de milho com diferentes LIs no aumento do teor de açúcares fermentescíveis. Assim, inicialmente, foi realizado o processo de polpação alcalina da palha, sendo verificados teores de lignina de $8,30 \%$ e 3,20 \% e de holocelulose de $66,79 \%$ e 95,26 \% nas palhas bruta e polpada, respectivamente, além da síntese e caracterização dos LIs acetato de sec-butilamônio, lactato de sec-butilamônio, acetato de n-butilamônio e lactato de n-butilamônio. Posteriormente, foi realizado o tratamento das palhas bruta e polpada com os LIs e hidrólise enzimática, sendo verificada uma razão mássica de glicose de até 17,57\% na palha polpada e tratada com o acetato de n-butilamônio, contra 3,98\% na palha somente polpada e, um aumento de até 90,7\% na razão mássica de açúcares fermentescíveis na palha tratada, em relação, a palha sem tratamento, sendo esta eficiência, maior, ao utilizar-se líquidos ionicos com o cátion n-butilamônio.
\end{abstract}

PALAVRAS-CHAVE: Resíduo lignocelulósico; Biocombustíveis; Líquido iônico; Hidrólise enzimática

\section{INTRODUÇÃ̃O}

Devido ao enorme consumo de combustíveis fósseis no dia-a-dia, observou-se um aumento na emissão de $\mathrm{CO}_{2}$, gerando grandes problemas ambientais. Sendo assim, estudos vêm sendo desenvolvidos buscando combustíveis alternativos, como o bietanol, que possibilitam a redução da emissão de gases, já que podem substituir e desempenhar o mesmo papel dos combustíveis atuais, com vantagens significativas quando comparados aos combustíveis fósseis (Elgharbawy et al., 2016; Klein et al., 2016; Sun et al., 2012).

Além disso, o desenvolvimento dessas pesquisas tem sido importante pelo fato de que algumas das matérias-primas utilizadas para produção dos biocombustíveis também serem utilizadas para o sustento e produção de alimentos para população, o que torna o processo competitivo. Dessa forma, uma solução encontrada pelos cientistas e empresas, foi a utilização de resíduos lignocelulósicos, que são produzidos a partir de materiais que, teoricamente, seriam descartados como, por exemplo, a palha de milho, o capim, o bambu, a 
alfafa, casca de arroz, a fibra de coco entre outros, o que favorece o reaproveitamento de resíduos (Zhou e Runge, 2015; Uju et al., 2015).

Porém, a sua aplicação para a produção desses biocombustíveis é considerada um pouco limitada devido a complexidade de suas estruturas, compostas por celulose, lignina e hemicelulose e, devido a esse fato, a obtenção das mesmas separadas uma das outras, não se torna um processo simples. Além disso, há o fato da proximidade das três camadas da parede celular presentes nos materiais vegetais, que dificulta ainda mais a sua separação (Ogeda et al., 2010).

Dessa forma, para a produção de bioetanol a partir desses resíduos, existe a necessidade da realização de tratamentos, sendo possível a utilização de tratamentos com ácidos, bases, biológicos e, atualmente, com líquidos iônicos, que vem mostrando uma elevada viabilidade em estudos realizados.

Com relação aos tratamentos possíveis, os tratamentos alcalinos, são caracterizados pela utilização do hidróxido de sódio, porém, também é possível a realização desse processo com outros álcalis, como hidróxido de cálcio e hidróxido de potássio. Destes, o tratamento com hidróxido de sódio é bastante eficiente, uma vez que aumenta a superfície interna da celulose e diminui a cristalinidade presente no material. Tratamentos alcalinos promovem menor solubilização da celulose e hemicelulose, quando comparado ao tratamento ácido (Singh et al., 2016).

Também se destaca o processo Kraft, desenvolvido em 1879 por Dahl, que consiste no tratamento da fibra bruta com uma solução de hidróxido de sódio (NAOH) e sulfeto de sódio $\left(\mathrm{Na}_{2} \mathrm{~S}\right)$, conhecida como licor branco que promove a quebra da lignina e, com isso, a deslignificação (Vivian, 2015, Oliveira, 2010).

Com relação aos tratamentos químicos em que se utilizam ácidos, os mais comuns neste tipo de processo são os que utilizam ácidos sulfúrico, clorídrico, acético e fosfórico diluídos para minimizar os problemas relacionados a corrosão dos equipamentos e, também, relacionados aos gastos provenientes da recuperação de ácidos concentrados. Destaca-se também outro benefício de se utilizar ácidos diluídos, que consiste no fato de evitar a formação de furfural e hidroximetilfurfural, considerados subprodutos de tratamentos ácidos (Singh et al., 2016).

Em pré-tratamentos biológicos, utiliza-se da tecnologia envolvendo microrganismos como fungos e bactérias, na produção de enzimas como, por exemplo, peroxidases e lacases. Através desses processos, essas enzimas removem a lignina da matriz lignocelulósica, permitindo uma maior eficiência no processo de hidrólise (Lorencini, 2013).

E, atualmente, muitos estudos têm sido realizados levando-se em consideração os tratamentos de materiais lignocelulósicos com líquidos iônicos, que possibilitam o aumento da disponibilidade de açúcares para o processo de fermentação ocasionada pela modificação do grau de cristalinidade, o aumento na área de contato disponível na etapa de hidrólise e, além disso, devido a remoção da lignina e a hemicelulose de maneira eficiente (Andrade Neto et al., 2016; Sun et al., 2012). 
Dessa forma, líquidos iônicos têm se mostrado ótimas alternativas no processo de prétratamento e hidrólise na produção de bioetanol. Esses materiais têm ação sobre as ligações de hidrogênio presentes nas fibras de celulose. Com isso, há o rompimento das ligações $\Pi$ $\Pi$ presentes entre a lignina e a matriz celulósica e, dessa forma, consegue-se uma boa separação entre esses componentes, o que leva a bons rendimentos no pré-tratamento, ao mesmo tempo que ocorre a modificação da cristalinidade da celulose (Andrade Neto et al., 2016).

Além disso, um tratamento utilizando líquidos iônicos, promove um bom revestimento da celulose e uma etapa livre de odores ou de toxicidade (Elgharbawy et al., 2012). E muito importante também ressaltar os benefícios ambientais do uso de líquidos iônicos, visto que é possível recuperação do solvente e, os mesmos apresentam baixa toxicidade (Ogeda et al., 2010).

Devido as características dos líquidos iônicos, várias pesquisas então sendo desenvolvidas utilizando-se os mesmos podendo ser destacadas a aplicação do acetato de 1etil-3-metilimidazólio, do cloreto de 1-butil-3-metilimidazólio e do acetato de $n$-butilamônio, que têm mostrado uma alta eficiência na remoção da lignina da biomassa. Ainda assim, muitos outros líquidos iônicos estão sendo sintetizados, sempre visando a redução de custos, melhor eficiência e menor impacto ambiental (Andrade Neto et al., 2016).

Assim, destacam-se os trabalhos desenvolvidos por Uju et al. (2015), que realizou estudos com líquidos iônicos no pré-tratamento de resíduos de algas da indústria. Neste trabalho, comparou-se o rendimento do tratamento com líquidos iônicos com o da biomassa tratada com ácido peracético e sem o tratamento com ácido. Utilizou-se os líquidos iônicos cloreto de 1-metil piridínio e 1-etil-3-metilimidazólio dietilfosfato.

De acordo com Bahrani et al. (2015), que também realizou trabalhos com líquidos iônicos, o pré-tratamento do bagaço de cana de açúcar com o líquido iônico 1,3dimetilfosfato de dimetilidazólio levou a uma conversão máxima de açúcares fermentescíveis de 70,38\%. No que se diz respeito à utilização da palha de milho como biomassa, estudos mostram que líquidos iônicos apresentam um bom desempenho no pré-tratamento do material lignocelulósico. Papa et al. (2015), comparou o rendimento do pré-tratamento com o líquido iônico 1-etil-3-metilimidazol, e do tratamento com processo hidrotérmico.

Os resultados revelaram uma maior eficiência do tratamento com líquidos iônicos, apresentando um maior rendimento na conversão da biomassa, e também na produção de biocombustíveis. Além disso, o bioetanol e o biometano produzidos com a amostra submetida ao tratamento com 1-etil-3-metilimidazol apresentaram um índice maior de energia total ( $\mathrm{kg} /$ sólidos totais), do que as amostras submetidas ao outro tratamento.

Andrade Neto et al. (2015), mostrou a eficiência do líquido iônico acetato de $n$ butilamônio no tratamento de fibra de coco. O estudo comparou a conversão de açúcares em amostras de fibra de coco bruta e polpada e fibra de coco polpada e, posteriormente, tratada com líquido iônico. As amostras polpadas e tratadas com acetato de $n$-butilamônio apresentaram rendimento de $89,75 \%$, seguido das amostras polpadas $(47,58 \%)$ e da fibra bruta $(8,53 \%)$. 
Assim, verifica-se que, a cada ano, novas pesquisas com líquidos iônicos têm sido publicadas, revelando, assim, a possibilidade de aplicação de líquidos iônicos no prétratamento de biomassa. Novos produtos são sintetizados e líquidos que já apresentaram eficiência são testados em outros substratos e em diferentes processos e, assim, auxiliam no desenvolvimento de soluções para a indústria.

Assim, ainda há muitos aspectos a serem elucidados, como, por exemplo, o efeito do teor de água, reciclo desses materiais e efeito da cinética das reações. Essas necessidades justificam a importância da inovação e novos estudos na área, trazendo soluções viáveis economicamente e que melhorem a eficiência de processos químicos (Elgharbawy et al., 2012).

Dessa forma, visando contribuir com as pesquisas que têm sido desenvolvidas, no presente estudo é demonstrada a eficiência do tratamento de palha de milho com diferentes líquidos iônicos (acetato de $n$-butilamônio, acetato de sec-butilamônio, lactato de $n$ butilamônio e lactato de sec-butilamônio) visando o aumento da concentração de açúcares fermentescíveis e, dessa forma, aumento no rendimento durante a obtenção de bioetanol a partir de resíduos lignocelulósicos.

\section{MATERIAIS E MÉTODOS}

\subsection{Materiais}

Para a realização da síntese dos líquidos iônicos, tratamentos da palha de milho e caracterizações foram adquiridos reagentes grau analítico: Ácido cítrico P.A (>= 99,5 \%), Ácido acético (>=99,8\%), Ácido sulfúrico (entre 95,00\% e 98,00\%), Hidróxido de sódio ( $>=97,0 \%$ ), Hidróxido de potássio ( $>=85,0 \%$ ), Acetona ( $>=99,5 \%$ ) e Etanol $(>=95,0 \%)$ foram adquiridos da Dinâmica reagentes (Campinas, SP, BR). Ácido lático $(85 \%)$ e $n$ butilamina $(>=99,0 \%$ ) foram adquiridos da Neon (São Paulo, SP, BR). Celulase (Trichoderma reesei ATCC 26921), Citrato de sódio (>= 99,0 \%), sec-butilamina P (99 \%), Clororfórmio Deuterado com $0.03 \%$ de TMS (99.6\%\%) e DNS (ácido 3,5-dinitro salicílico) foram adquiridos da Sigma Aldrich (St. Louis, MO, USA) e Clorito de sódio ( $>=78,0$ \%) foi adquirido da Merck (Darmstadt, Hesse, GER).

\subsection{Métodos}

Síntese dos líquidos iônicos: Os líquidos iônicos acetato de $n$-butilamônio, acetato de sec-butilamônio, lactato de $n$-butilamônio e lactato de sec-butilamônio foram obtidos através da reação de neutralização ácido-base 1:1 (molar) dos ácidos carboxílicos (ácido acético ou ácido lático) com as aminas ( $n$-butilamina, sec-butilamina). Na produção dos líquidos, a adição do ácido carboxílico foi realizada, lentamente, sob a amina, em banho de gelo, controlando-se a temperatura entre 20 e $30^{\circ} \mathrm{C}$ sob agitação de $200 \mathrm{rpm}$ sendo utilizado, para isso, um agitador mecânico modelo 713D Fisatom (São Paulo, SP, BR).

Finalizada a adição do ácido, o sistema foi mantido sob agitação durante 1 hora para finalização da reação e armazenados, em fracos âmbar, posteriormente, por 48 h. Após esse período, os mesmos foram caracterizados via Ressonância Magnética Nuclear de Hidrogênio $\left(\mathrm{RMNH}^{1}\right)$ e de Carbono $\left(\mathrm{RMNC}^{13}\right)$ em um Espectrômetro de RMN Bruker Avance III 600 
HD (Ettlingen, Baden-Württemberg, GER) localizado no Instituto de Química, UNESP, Araraquara. $\mathrm{O}$ solvente utilizado foi o clorofórmio deuterado $\left(\mathrm{CDCl}_{3}\right)$ contendo $0,03 \%$ de tetrametilsilano (TMS).

Polpação da palha de milho: Inicialmente, a palha de milho foi lavada e seca em uma estufa Quimis (Diadema, SP, BR) à temperatura de $80^{\circ} \mathrm{C}$ por 24 horas, aproximadamente. Em seguida, com o auxílio de um moinho de facas tipo Willy TE-6500 da Tecnal (Piracicaba, SP, BR), foi feita a redução do tamanho de partícula, através da trituração da palha seca. Após essa etapa, foi realizada a polpação da palha em um reator 5 litros da Metalquim (São Paulo, SP, BR).

Nesta etapa, foram adicionados 3 litros de solução de hidróxido de sódio $8 \%(\mathrm{~m} / \mathrm{m})$ para cada $400 \mathrm{~g}$ de palha. $\mathrm{O}$ tempo de reação foi de 6 horas, à temperatura de $137{ }^{\circ} \mathrm{C}$, à pressão de 2,5 atm e a rotação de $120 \mathrm{rpm}$. Finalizada a polpação, o produto foi lavado com água em abundância até eliminação de todo o resíduo de hidróxido de sódio e seco em estufa à $75^{\circ} \mathrm{C}$ por 24 horas.

Tratamento da palha de milho bruta e polpada com os líquidos iônicos: Para a realização do tratamento da palha, bruta ou polpada, com os líquidos iônicos, utilizou-se uma proporção de 1:10 (palha: líquido iônico). Os experimentos foram realizados em balão de fundo redondo, sendo o sistema montado em banho de óleo de silicone Quimis (Diadema, $\mathrm{SP}, \mathrm{BR})$ a $120^{\circ} \mathrm{C}$ mantido sob agitação sendo utilizado, para isso, um Agitador Mecânico Fisatom (São Paulo, SP, BR) operando a 180 rpm.

Esse processo teve tempo de duração de 25 horas sendo cada tratamento realizado em duplicata (Tabela 1). Após o término do tratamento, foi realizada a filtração e lavagem do produto até eliminação total de resíduos de líquido iônico sendo, posteriormente seco em estufa à $70^{\circ} \mathrm{C}$ por um período de 24 horas, aproximadamente.

Tabela 1 - Amostras tratadas com os líquidos iônicos estudados

\begin{tabular}{ccc}
\hline Experimento & Material lignocelulósico & Líquido iônico \\
\hline $\mathbf{1}$ & Palha de milho bruta & acetato de $n$-butilamônio \\
$\mathbf{2}$ & Palha de milho bruta & acetato de $s e c$-butilamônio, \\
$\mathbf{4}$ & Palha de milho bruta & lactato de $n$-butilamônio, \\
$\mathbf{5}$ & Palha de milho bruta & lactato de $s e c$-butilamônio \\
$\mathbf{6}$ & Palha de milho polpada & acetato de $n$-butilamônio \\
$\mathbf{7}$ & Palha de milho polpada & acetato de $s e c$-butilamônio, \\
$\mathbf{8}$ & Palha de milho polpada & lactato de $n$-butilamônio, \\
& Palha de milho polpada & lactato de $s e c$-butilamônio \\
\hline
\end{tabular}

Caracterização da palha bruta, polpada e tratada com os líquidos iônicos: Durante a caracterização dos materiais lignocelulósicos, foram determinados os teores de umidade, cinzas, lignina, holocelulose das palhas bruta e polpada, submetidas ou não ao tratamento com os líquidos iônicos. Também foram realizadas análises da fibra bruta e polpada via microscopia eletrônica de varredura em um Microscópio Eletrônico de Varredura Obducat CamScan CS 3200 LV Shimadzu (Kiyamachi-Nijo, Kyoto, JP). 
Para a determinação do teor de umidade e de cinzas, seguiu-se a metodologia descrita por Morais et al., 2010. Já, para a determinação do teor de holocelulose foi utilizada uma adaptação da metodologia descrita por Wise e Murphy (1946) sendo determinada, a partir da holocelulose, os teores de celulose e de hemicelulose utilizando a metodologia descrita por Trugilho et al., 2005. Para a determinação do teor de lignina insolúvel foi utilizada a norma TAPPI Test Method T222 os-76 (1979).

As análises das superfícies da palha bruta e polpada foram obtidas em um Microscópio Eletrônico de Varredura (MEV) Shimadzu modelo Obducat CamScan CS 3200 LV (Figura 12), utilizando-se uma voltagem de aceleração de $20 \mathrm{kV}$ e ampliações de 1000x sendo que, as amostras foram submetidas a metalização com ouro para se garantir a boa condutividade. Foram obtidas imagens da superfície do material lignocelulósico e também das extremidades para verificação das modificações após o tratamento de polpação.

Hidrólise enzimática da palha bruta, polpada e tratada com os líquidos iônicos: Após o tratamento com o líquido iônico, foi realizada a hidrólise enzimática de cada um dos materiais, em duplicata. Para isso, foram utilizados $10 \mathrm{ml}$ de tampão citrato de sódio 0,1 $\mathrm{mol} / \mathrm{l} \mathrm{pH} \mathrm{6;0,5} \mathrm{g} \mathrm{de} \mathrm{cada} \mathrm{substrato} \mathrm{e} 3,3 \mathrm{ml}$ de solução de celulase (Trichoderma reesei ATCC 26921) (2 g/l). A temperatura da hidrólise foi de $44^{\circ} \mathrm{C}$, o tempo de reação de 40 horas e a agitação de $200 \mathrm{rpm}$. Todas as reações foram processadas em uma Incubadora Shaker Innova 43 da New Brunswick Scientific (Hamburg, GER)sendo, após a finalização da hidrólise, filtradas à vácuo e o filtrado submetido a análises via HPLC, em um Cromatógrafo Shimadzu (Kiyamachi-Nijo, Kyoto, JP) para a determinação da concentração de glicose presente nos hidrolisados.

Para isso, foi utilizada uma fase móvel composta por água com 0,005 \% de ácido sulfúrico, um fluxo 0,5 ml/min e uma coluna Bio Rad® (Berkeley, California, USA) Aminex ® HPX 87H 300X7,8 mm com pré coluna . O detector utilizado foi o de Índice de Refração. Também foram realizadas análises dos hidrolisados pelo método do DNS (ácido 3,5-dinitro salicílico), para a determinação da quantidade de açúcares redutores totais presentes nos hidrolisados sendo utilizada, para isso, uma adaptação da metodologia descrita por Miller (1959).

\section{RESULTADOS E DISCUSSÕES}

\subsection{Síntese e caracterização dos líquidos iônicos}

Todos os reagentes utilizados (n-butilamina, sec-butilamina, ácido láctico e ácido acético) e líquidos iônicos obtidos (acetato de $n$-butilamônio, o acetato de sec-butilamônio, o lactato de $n$-butilamônio e o lactato de sec-butilamônio) (Figura 1) foram caracterizados via RMN. Através da análise de espectros de $\mathrm{RMNH}^{1}$, observa-se um deslocamento do sinal referente ao grupo amino após a protonação e formação do cátion amônio de 0,93 e 1,42 ppm para 7,60; 7,60; 5,50 e 5,35 ppm, respectivamente ao se obter os líquidos iônicos acetato de $n$-butilamônio, o acetato de sec-butilamônio, o lactato de $n$-butilamônio e o lactato de secbutilamônio o que confirma a formação dos mesmos. A atribuição dos demais sinais auxiliaram na confirmação da formação dos líquidos iônicos desejados sendo a mesma comparada com dados da literatura (Andrade Neto et al., 2016; Silverstein et al., 2007) 


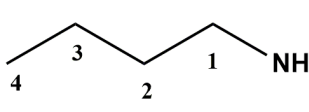

(1)<smiles>CCCCNCOC(C)=O</smiles>

(5)<smiles>CCCCNC[O+]C(=O)C(C)O</smiles>

(7)<smiles>CC(O)C(=O)O</smiles>

(3)<smiles>CCC(C)N[O+]C(C)=O</smiles>

(6)<smiles>CC[C@H](C)N[O+]C(=O)C(C)O</smiles>

(8)

Figura 1 - Estruturas das aminas, ácidos carboxílicos e líquidos iônicos: 1) $n$-butilamina, 2) secbutilamina, 3) ácido acético, 4) ácido láctico, 5) acetato de $n$-butilamônio, 6) acetato de sec-butilamônio, 7) lactato de $n$-butilamônio, 8) lactato de sec-butilamônio.

(1) n-butilamina: $\mathrm{RMNH}^{1}(600 \mathrm{MHz}, \mathrm{CDCl} 3)$ : $\delta$ 2,69 (2H, t, H-1), 1,44 (2H, m, H-2), 1,35 (2H, m, H-3), 0,92 $(3 \mathrm{H}, \mathrm{t}, \mathrm{H}-4)$ 1,42 (s, 2H, NH ). RMNC ${ }^{13}$ (150 MHz, CDCl3): $\delta$ 42,04 (C-1), 36,09 (C-2), 20,09 (C-3) e 14,01(C4).

(2) sec-butilamina: $\mathrm{RMNH}^{1}(600 \mathrm{MHz}, \mathrm{CDCl} 3): \delta$ 0,69 (3H, d, H-1), 2,44 (1H, m, H-2), 0,99 e 1,01 (2H, m, H3), 0,56 (3H, t, H-4), 0,93 (s, 2H, NH$). \mathrm{RMNC}^{13}$ (150 MHz, CDCl3): $\delta$ 22,94 (C-1), 47,98 (C-2), $32,33(\mathrm{C}-3) \mathrm{e}$ $10,01(\mathrm{C}-4)$.

(3) Ácido acético: $\mathrm{RMNH}^{1}$ (600 MHz, CDCl3): $\delta$ 2,11 (2H, s, H-2). RMNC ${ }^{13}$ (150 MHz, CDCl3): $\delta$ 177,65 (C1) e 21,21 (C-2).

(4) Ácido lático: $\mathrm{RMNH}^{1}$ (600 MHz, CDCl3): $\delta$ 4,38 (1H, m, H-2) 1,42 (3H, d, H-3). RMNC ${ }^{13}(150 \mathrm{MHz}$, CDCl3): $\delta$ 180,05 (C-1), 66,68 (C-2) e 20,49 (C-3).

(5) Acetato de $n$-butilamônio: $\mathrm{RMNH}^{1}(600 \mathrm{MHz}, \mathrm{CDCl} 3)$ : $\delta$ 2,76 (3H, s, H-2), 1,86 (2H, t, H-3), 1,56 (2H, m, $\mathrm{H}-4), 1,35$ (2H, m, H-5), 0,89 (3H, t, H-6), 7,60 (3H, s, $\left.\mathrm{NH}_{3}^{+}\right) . \mathrm{RMNC}^{13}$ (150 MHz, CDCl3): $\delta$ 179,05 (C-1), 30,52 (C-2), 39,73 (C-3), 24,67 (C-4), 19,91 (C-5), 14,48 (C-6).

(6) Acetato de sec-butilamônio: $\mathrm{RMNH}^{1}(600 \mathrm{MHz}, \mathrm{CDCl} 3)$ : $\delta$ 2,96 (3H, s, H-2), 1,90 (3H, d, H-3), 1,02 (1H, m, H-4), 1,0 (2H, dm, H-5), 1,19 (3H, t, H-6), 7,26 (3H, s, $\left.\mathrm{NH}_{3}^{+}\right) . \mathrm{RMNC}^{13}$ (150 MHz, CDCl3): $\delta$ 179,22 (C-1), 30,03 (C-2), 48,79 (C-3), 25,07 (C-4), 20,00 (C-5), 10,32 (C-6).

(7) Lactato de $n$-butilamônio: $\mathrm{RMNH}^{1}(600 \mathrm{MHz}, \mathrm{CDCl} 3)$ : $\delta$ 4,00 (1H, m, H-2), 1,29 (3H, d, H-3), 2,79 (2H, t, $\mathrm{H}-4), 1,56$ (2H, m, H-5), 1,35 (2H, m, H-6), 0,90 (3H, t, H-7), 5,50 (3H, d, $\left.\mathrm{NH}_{3}{ }^{+}\right) . \mathrm{RMNC}^{13}$ (150 MHz, CDCl3): $\delta$ 181,53 (C-1), 68,85 (C-2), 18,39 (C-3), 48,74 (C-4), 27,97 (C-5), 21,35 (C-6), 10,52 (C-7).

(8) Lactato de sec-butilamônio: $\mathrm{RMNH}^{1}(600 \mathrm{MHz}, \mathrm{CDCl} 3)$ : $\delta 3,98$ (1H, m, H-2), 1,33 (3H, d, H-3), 1,24 (3H, d, H-4), 3,08 (1H, m, H-5), 1,52-1,67 (2H, dm, H-6), 0,96 (3H, t, H-7), 5,35 (3H, s, $\left.\mathrm{NH}_{3}^{+}\right) . \mathrm{RMNC}^{13}(150 \mathrm{MHz}$, CDCl3): $\delta$ 181,77 (C-1), 69,08 (C-2), 21,26 (C-3), 18,92 (C-4), 48,68 (C-5), 28,93 (C-6), 10,18 (C-7). 


\subsection{Polpação e tratamento com os líquidos iônicos da palha de milho}

Finalizada a síntese dos líquidos iônicos (LI), iniciou-se a polpação e o tratamento da palha de milho com os LI sintetizados. Após o processo de polpação, foram obtidos 105 gramas de palha polpada, o que mostra uma perda de massa de aproximadamente $74 \%$, devido, ao pré-tratamento alcalino, que pode ter provocado eliminação de componentes solúveis, degradação da hemicelulose e da própria celulose bem como as perdas durante a etapa de filtração. Com relação as caracterizações químicas referentes a composição majoritária, foram determinados os teores de umidade $(8,25 \pm 0,21$ e 6,65 $\pm 0,07)$, cinzas $(1,67 \pm 0,05$ e $0,845 \pm 0,16)$, holocelulose $(66,79 \pm 1,70$ e $95,26 \pm 1,15)$, celulose $(44,26 \pm$ $0,74$ e $93,90 \pm 0,64)$, hemicelulose $(22,53 \pm 0,50$ e 1,36 $\pm 0,51)$ e lignina insolúvel $8,3 \pm 0,23$ e $3,2 \pm 0,07)$, para as fibras bruta e polpada, respectivamente.

Salienta-se também que os teores de umidade verificados são aceitáveis, uma vez que os resultados da literatura mostram valores inferiores a 10\% de umidade para a realização da caracterização de materiais lignocelulósicos (ROJAS,2012).

Também foi possível verificar mudanças significativas na superfície da fibra após a polpação através da análise das micrografias (Figura 2), sendo identificado que as fibrilas de celulose se encontram menos aderidas umas às outras pela ação da lignina, confirmando a deslignificação após o processo.

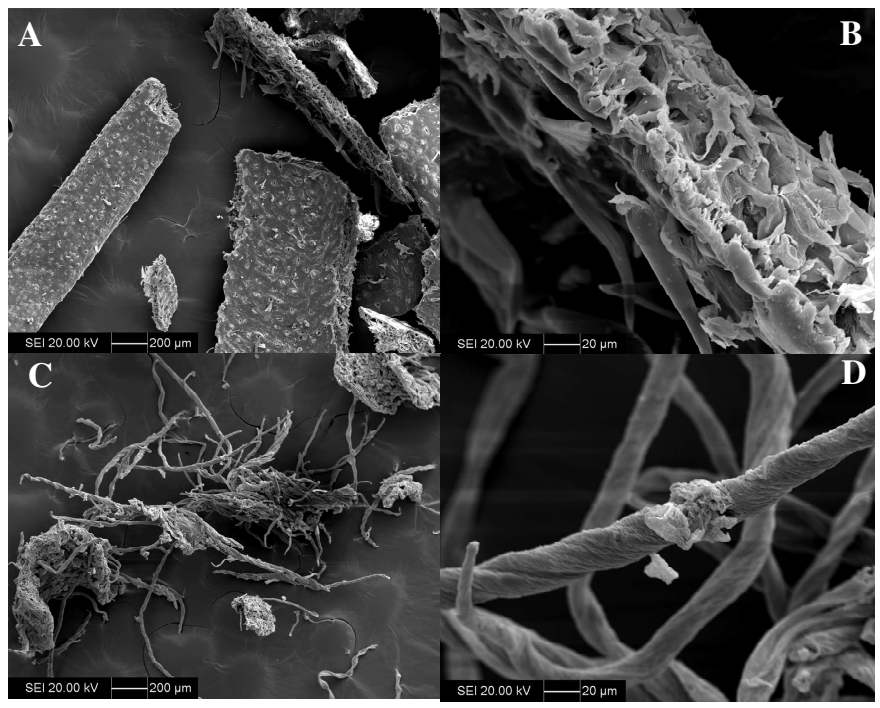

Figura 2 - Palha de milho bruta (A e B) e polpada (C e D).

Com relação aos tratamentos das palhas de milho bruta e tratada com os líquidos iônicos acetato de $n$-butilamônio, acetato de sec-butilamônio, lactato de $n$-butilamônio e lactato de sec-butilamônio, verificou-se que a palha de milho bruta se mostrou bem mais escura após a realização do tratamento com os líquidos iônicos. Esse fato pode ser explicado pela formação de melanoidinas. Esses compostos possuem coloração escura e são compostos intermediários da reação de escurecimento não enzimático conhecida como reação de Maillard. 
Essa reação acontece entre os açúcares redutores e aminoácidos ou proteínas, através dos rearranjos de Amadori e Heyns (Bobbio, 1989). Com relação a amostra polpada submetida ao tratamento com os líquidos iônicos verifica-se que o processo de tratamento com os líquidos iônicos proporcionou a obtenção de uma palha mais clara, o que pode ser justificado, possivelmente, pela redução de resíduos de lignina após a polpação bem como dos açúcares livres (Figura 3).

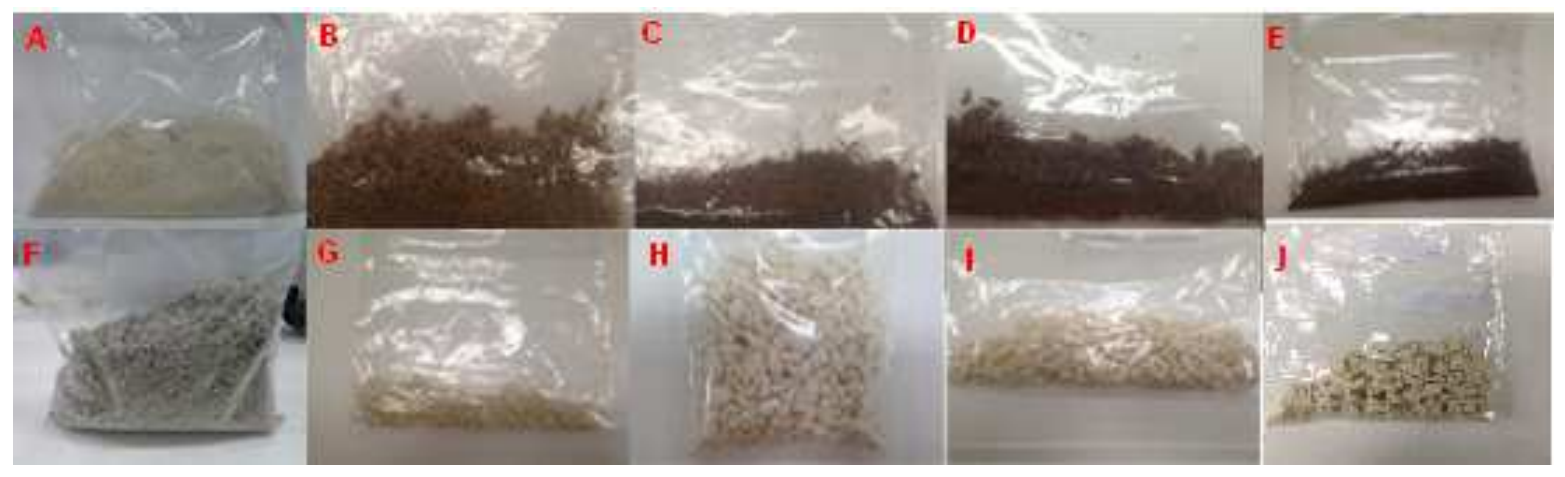

Figura 3 - (A) palha bruta; (B) palha bruta tratada com acetato de $n$-butilamônio; (C) palha bruta tratada com acetato de sec-butilamônio; (D)palha bruta tratada com lactato de $n$ butilamônio, (E) palha bruta tratada com lactato de sec-butilamônio; (F) palha polpada; (G) palha polpada tratada com acetato de sec-butilamônio; $(\mathrm{H})$ palha polpada tratada com lactato de $n$-butilamônio, (I) palha polpada tratada com lactato de sec-butilamônio, (J) palha polpada tratada com acetato de $n$-butilamônio

Também foi verificada uma redução no teor de cinzas e de lignina insolúvel, conforme esperado, uma vez que, tanto a polpação como os tratamentos com os líquidos iônicos, promovem a eliminação da lignina e de compostos inorgânicos solúveis, principalmente ao utilizar-se o líquido iônico acetato de $n$-butilamônio, que levou a uma redução no teor de lignina de $8,3 \pm 0,23 \%$ na palha bruta para $6,33 \pm 0,09 \%$ na palha bruta e tratada com o líquido iônico e, de 3,27 $\pm 0,07 \%$ na palha polpada para 1,55 $\pm 0,04 \%$ para a palha polpada e submetida ao tratamento com o mesmo líquido iônico.

Em relação aos teores de lignina insolúvel obtidos, ainda foi possível analisar que, o pré-tratamento alcalino foi eficiente, pois pode ser verificada uma diminuição de $61,45 \% \mathrm{em}$ média, no teor de lignina da palha bruta para a mesma após o pré-tratamento, comprovando que houve a degradação parcial da matriz de lignina, assim como de hemicelulose. Observase, também, que o teor de lignina insolúvel diminuiu após a realização do tratamento com os LIs, principalmente no caso da utilização do acetato de $n$-butilamônio.

Com relação ao teor de cinzas, foi verificado uma redução de $1,67 \pm 0,05 \%$ para 0,47 $\pm 0,05 \%$ da palha bruta para a palha tratada com o líquido iônico e de $0,84 \pm 0,16 \%$ para $0,32 \pm 0,03 \%$ ao analisar-se a palha polpada e submetida ao tratamento com o LI acetato de n-butilamônio.

Também foi verificado, no caso da palha de milho bruta, um aumento no teor de holocelulose $(66,79 \pm 1,70 \%$ e $84,19 \pm 1,41 \%)$ e de celulose $(44,26 \pm 0,74 \%$ e $51,18 \pm$ $0,93 \%$ ) após a realização do tratamento com o LI acetato de $n$-butilamônio, devido a deslignificação e redução das concentrações de compostos inorgânicos e, no caso da palha de 
milho polpada, uma pequena redução dos teores de holocelulose $(95,26 \pm 1,15 \%$ e $92,44 \pm$ $0,32 \%)$ e de celulose $(93,90 \pm, 63 \%$ e $90,88 \pm 0,01 \%)$.

Esse fato pode ser explicado devido a maior disponibilidade da celulose e hemicelulose após a realização do processo e que leva a maior decomposição de ambas após a realização do tratamento com o LI. Deve ser ressaltada, também, a eliminação de compostos inorgânicos durante o processo de polpação, que favorece a obtenção de uma maior concentração de holocelulose no material submetido ao posterior tratamento com o líquido iônico.

Com relação a holocelulose, deve ser destacado também que, a literatura apresenta um valor de 57,49\% (Salazar et al, 2005) e, como pode ser observado, os resultados obtidos foram superiores ao esperado. Isso pode ser explicado pelo baixo teor de lignina verificado e, também, pelo baixo teor de cinzas e, ainda, pelo elevado teor de umidade.

\subsection{HIDRÓliSe ENZIMÁtica DA PALHA BRUTA, POLPADA E TRATADA COM OS LÍQUIDOS IÔNICOS}

Após a realização dos tratamentos das palhas de milho bruta e polpada, foi realizada a hidrólise enzimática de todos os materiais vegetais sendo que, os hidrolisados foram caracterizados para determinação das porcentagens mássicas de glicose e de açúcares redutores totais.

Com relação aos materiais obtidos após a realização da hidrólise, verificou-se as maiores razões mássicas de glicose a partir da palha polpada tratada com os líquidos iônicos, principalmente, com o acetato de $n$-butilamônio, obtendo-se para o mesmo, uma razão mássica de glicose de 17,57\%, em detrimento, da palha bruta sem tratamento de apenas, $3,95 \%$, um aumento interessante de $77,52 \%$ de massa de glicose. Outras duas amostras que também evidenciaram a vantagem da polpação, foram as tratadas com o acetato de secbutilamônio com um aumento na razão de $41,58 \%$ da palha polpada, em relação, a palha bruta, e com o lactato de $n$-butilamônio, com um aumento de $55,61 \%$ da palha polpada, em relação, a palha bruta. Vale ressaltar também que os tratamentos realizados pelos líquidos iônicos provenientes de aminas primárias, apresentaram resultados melhores que os tratamentos realizados pelos líquidos iônicos provenientes de aminas secundárias (Figura 4).

Também foi realizada uma análise, utilizando o reativo de DNS para determinação da concentração de açúcares redutores, para confirmação da eficiência do acetato de $n$ butilamônio, em detrimento, dos demais líquidos iônicos.

A partir dos dados obtidos, analisando-se primeiramente o comportamento das amostras sem tratamento com nenhum dos líquidos iônicos, observa-se com maior evidência novamente, a vantagem de se realizar a etapa de polpação, onde a razão mássica de açúcares redutores da palha polpada, supera, consideravelmente, a concentração de açúcares redutores obtida na palha bruta, com um aumento de $47,91 \%$ na porcentagem mássica.

Ao analisar os tratamentos realizados, em especial, com o acetato de $n$-butilamônio, observa-se que a palha bruta, por sua vez, apresentou melhor rendimento de açúcares redutores (Figura 5), embora a palha polpada tenha apresentado no tratamento com o mesmo 
líquido, maior concentração de glicose.

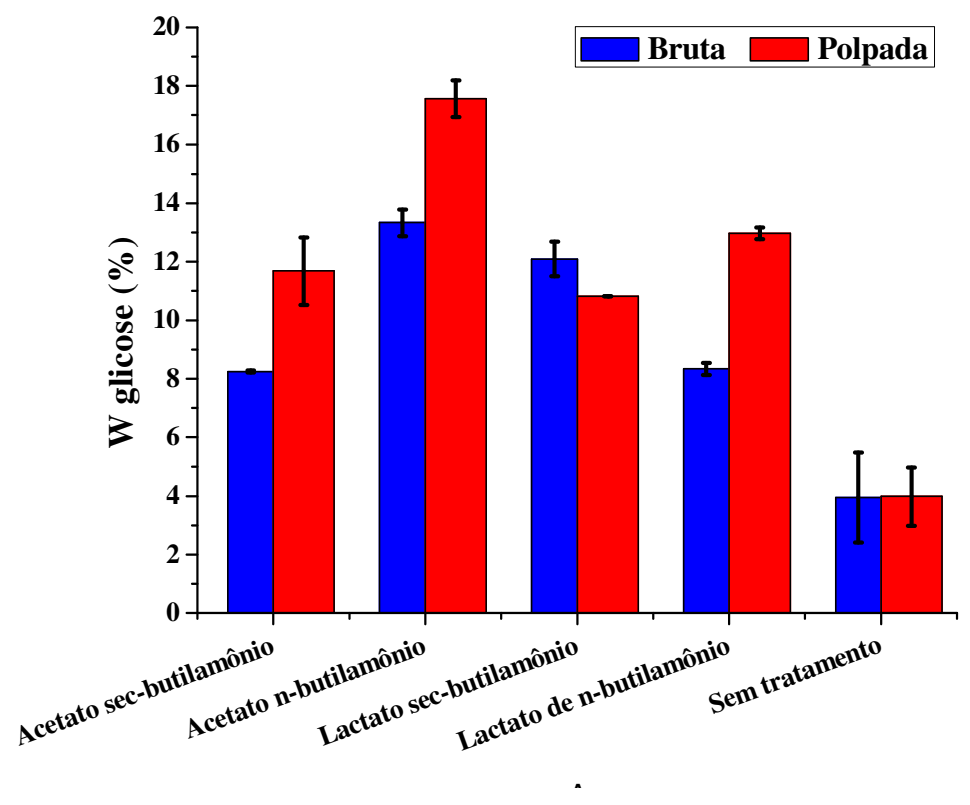

Figura 4 - Comparação das razões mássicas percentuais de glicose obtidas via HPLC.

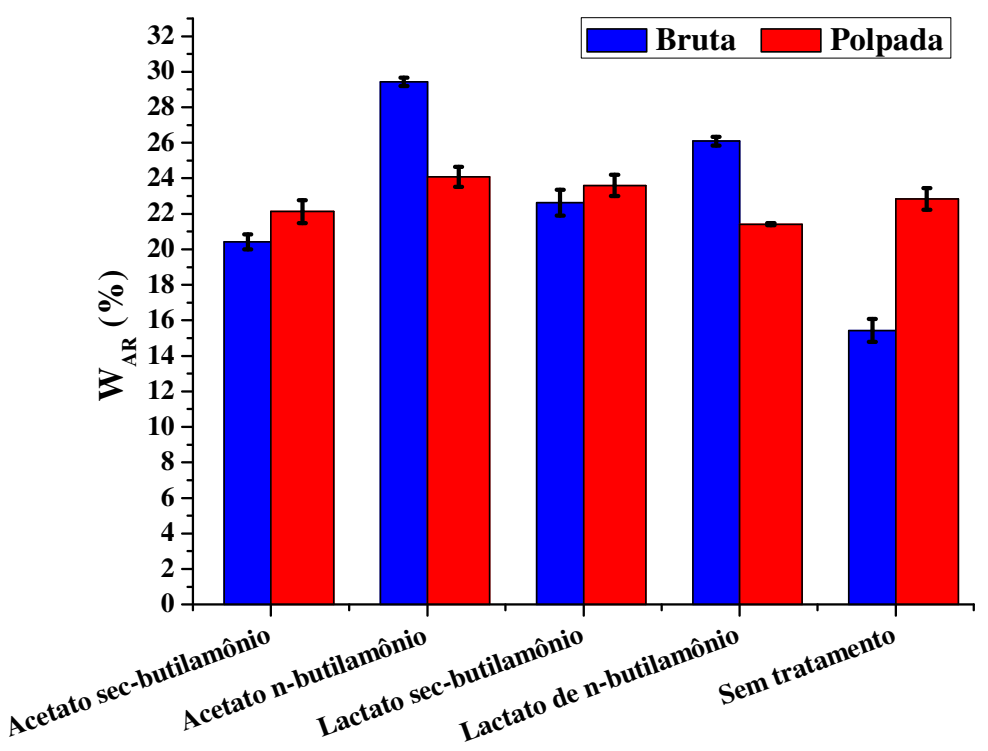

Figura 5 - Comparação das razões mássicas percentuais de açucares fermentescíveis obtidas pelo método DNS.

Observa-se que a razão mássica de açúcares redutores presentes na palha bruta e tratada, é significativamente maior do que na palha bruta sem tratamento, com um aumento de até 90,7\%, no caso, do tratamento com o acetato de $n$-butilamônio, em detrimento, a ausência de tratamento. Todavia, para a palha polpada, os tratamentos com os líquidos iônicos não demonstraram grandes vantagens, em termos de aumento de açúcares redutores, onde a maior razão mássica percentual obtida, foi também, para o acetato de $n$-butilamônio, que ainda assim, teve um aumento de $5,52 \%$ em relação a palha polpada sem tratamento. 
Somente, no caso, dos tratamentos com o lactato e o acetato de sec-butilamônio, a porcentagem mássica de açucares foi relativamente maior para a palha polpada. Contudo, o acetato e lactato de $n$-butilamônio aumentam a porcentagem de açúcares redutores na palha bruta. No caso da palha polpada, assim, como na palha bruta, o tratamento realizado com o acetato de $n$-butilamônio, proporcionou aumento tanto na razão mássica de glicose, quanto de açúcares redutores, em relação, aos demais líquidos iônicos.

\section{CONCLUSÕES}

Através da análise dos resultados obtidos, verificou-se uma elevada perda de massa após a polpação, cerca de $74 \%$, possivelmente, devido ao pré-tratamento alcalino, provocando degradação da hemicelulose e da matriz de lignina.

Também foi verificada a eficiência durante a síntese do líquido iônicos que foram utilizados no tratamento da palha de milho. O que garantiu essa eficiência, foram as caracterizações dos mesmos via $\mathrm{RMNH}^{1}$ e $\mathrm{RMNC}^{13}$ pelos quais foram obtidos dados concretos sobre todas as estruturas dos líquidos iônicos sintetizados.

Em relação as hidrólises realizadas após os tratamentos, foi observado que as amostras das palhas polpadas apresentaram maiores valores de porcentagem mássica de glicose em comparação as palhas brutas, com exceção das amostras tratadas com lactato de secbutilamônio sendo que, o tratamento que apresentou melhor resultado, foi o da amostra da palha polpada tratada com acetato de $n$-butilamônio (17,57\% em massa de glicose), sendo maior que da palha polpada sem tratamento $(3,98 \%$ em massa de glicose).

Além disso, pela análise utilizando-se DNS verificou-se também maior presença de açúcares redutores nas palhas brutas, sendo que a amostra que apresentou melhores resultado de porcentagem mássica de açúcares redutores foi a palha bruta tratada com acetato de $n$ butilamônio $(29,428 \%$ em massa), maior que a palha bruta sem tratamento $(15,434 \%$ em massa de açúcares redutores). Isso se justifica pelo fato de que, a enzima utilizada, a Celulase, é um conjunto de enzimas que hidrolisam a celulose, e neste caso, uma das enzimas que faz parte deste grupo, a endoglucanase age na região interna da fibra de celulose, liberando açúcares diferentes da glicose, como celobiose, celotriose, celotetrose e celopentose.

\section{AGRADECIMENTOS}

Ao Centro Universitário FEI pelo suporte para o desenvolvimento do trabalho.

\section{REFERÊNCIAS}

ANDRADE, A.M.; PASSOS, P.R.A.; MARQUES, L.G.C.; OLIVEIRA, L.B.; VIDAURRE, G.B.; ROCHA, J.D.S. Synthesis and characterization of new low-cost ILs based on butylammonium cation and application to lignocellulose hydrolysis. Carbohydrate Polymers, v.143, p.279-287, 2016.

BAHRANI, S; RAEISSI, S; SARSHAR, M. Experimental investigation of ionic liquid pretreatment of sugarcanebagasse with 1,3-dimethylimadazolium dimethyl phosphate. Bioresource Technology, v.185, p. 411-415, 2015. 
BOBBIO, Florinda; BOBBIO, Paulo. Introdução à Química de Alimentos. 2. Ed. São Paulo: Livraria Varela, 1989.

ELGHARBAWY, A.A.; ALAM, M.Z.; MONIRUZZAMAN, M.; GOTO, M. Ionic liquid pretreatment as emerging approaches for enhanced enzymatic hydrolysis of lignocellulosic biomass: Ionic liquid pretreatment boosts the yields. Biochemical Engineering Journal, v. 109, p.252-267, 2016.

KLEIN, M.; GRIESS, O.; PULIDINDI, I.N.; PERKAS, N.; GEDANKEN, A. Bioethanol production fromFicus religiosaleaves using microwave irradiation. Journal of Environmental Management, v. 177, p. 20-25, 2016.

LORENCINI, P. Otimização do pré-tratamento ácido de bagaço de cana para a sua utilização como substrato na produção biológica de hidrogênio. 2013. Dissertação (Mestrado em Química) - Universidade de São Paulo, Ribeirão Preto, 2013.

MILLER, G.L. Use of Dinitrosalicylic Acid Reagent of Determination of Reducing Sugar. Analytical Chemestry, v. 31 (3), 2002, p 426-428.

MORAIS, J.P.S., ROSA, M.F., MARCONCINI, J.M. Procedimentos para Análise

Lignocelulósica. Embrapa, Campina Grande, PB, 2010.

OLIVEIRA, F. Avaliação de diferentes pré-tratamentos e deslignificação alcalina na sacarificação da celulose de palha de cana. 2010. Dissertação (Mestrado em Conversão de Biomassa) - Escola de Engenharia de Lorena, Universidade de São Paulo, Lorena.

OGEDA, T. L.; PETRI, D.F.S. Hidrólise enzimática de biomassa, Química Nova, v. 33, n. 7, p.1549-1558, 2010.

PAPA, G.; RODRIGUEZ, S.; GEORGE, A.; SCHIEVANO, A.; ORZI ,V.; SALE, K.L.; SINGH, S.; ADANI, F.; SIMMONS, B.A. Comparison of different pretreatments for the production of bioethanol and biomethane from corn stover and switchgrass. Bioresource Technology, v. 183, p.101-110, 2015.

ROJAS, M. J. Produção de etanol e hidrolisado protéico da casca de soja. 2012. Dissertação (Mestrado em Engenharia Química) - Universidade Federal de São Carlos, São Carlos.

SILVERSTEIN, R.; WEBSTER, F.; KIEMLE, D. Identificação espectrométrica dos compostos orgânicos. 7. ed. Rio de Janeiro: LTC, 2007.

SALAZAR, R.F.S.; SILVA, G.L.P.; SILVA, M.L.C.P. Estudo da composição da palha de milho para posterior utilização como suporte na preparação de compósitos. 2005, FAENQUIL. VI Congresso Brasileiro de Engenharia Química em Iniciação Científica. SINGH, R.; SRIVASTAVA, M.; SHUKLA, A. Environmental sustainability of bioethanol production from rice straw in India: A review. Renewable and Sustainable Energy Reviews, v. 54, p. 202-216, 2016.

SUN, S.N.; LI, M.F.;YUAN, T.Q.; XU, F.; SUN, R.C. Effect of ionic liquid/organic solvent pretreatment on the enzymatic hydrolysis of corncob for bioethanol production. Part 1: Structural characterization of the lignins. Industrial Crops and Products, v. 43, p.570577, 2013.

TECHNICAL ASSOCIATION OF THE PULP AND PAPER INDUSTRY - TAPPI. Official test methods, provisional test methods, and useful test methods: fibrous material and pulp testing. Atlanta, 1979.

TRUGILHO, P.F.; BIANCHI, M.L.; GOMIDE, J.L.; LIMA, J.T.; MENDES, L.M.; MORI, F.A.; GOMES, D.F.F. Clones de Eucalyptus versus a produção de polpa celulósica. Ciência Florestal, v. 15, n. 2, p. 145-155, 2005.

UJU; WIJAYANTA, A.T.; GOTO,M.; KAMIYA, N. Great potency of seaweed waste biomass from the carrageenan industry for bioethanol production by peracetic acid- 
ionic liquid pretreatment. Biomass and Bioenergy, v. 81, p. 63-69, 2015.

VIVIAN, M. A. Aumento da eficiência do processo Kraft de polpação a partir de prétratamento de cavacos de madeira de eucalipto. 2015. Tese (Doutorado em Ciências) Universidade de São Paulo (USP). Escola Superior de Agricultura Luiz de Queiroz Piracicaba.

WISE, L.E.M.; MURPHY, A.A.D. Chlorite holocellulose, its fractionation and bearing on summative wood analysis and on studies on the hemicellulose. Paper Trade Journal, v. 122(2), p. 35-43, 1946.

ZHOU, S.; RUNGE, T. M. Mechanism of improved cellulosic bio-ethanol production from alfalfa stems via ambient-temperature acid pretreatment. Bioresource Technology, v. 193, p.288-296, 2015.

\title{
INFLUENCE OF IONIC LIQUIDS IN THE TREATMENT OF CORN STRAW FOR THE PRODUCTION OF BIOETHANOL
}

\author{
A. A. MORNDIM-GIANNETTI ${ }^{1,{ }^{*}, \text { P. R. } \text { CAMPOS }^{1} \text {, A. P. VIANA }}{ }^{1}$, R. P. T. MARTINEZ ${ }^{1}$, \\ M. DAMINATO ${ }^{1}$, R. C. SILVA $^{1}$ e M. A. SANTORO ${ }^{1}$ \\ ${ }^{1}$ FEI University, Department of Chemical Engineering \\ *E-mail: preamorandim@fei.edu.br
}

\begin{abstract}
This study proposes to verify the efficiency of the treatment of corn straw with different ILs when increasing the fermentable sugars content. Therefore, the alkaline pulping process of the straw was carried out, with lignin contents of $8.30 \%$ and $3.20 \%$ and holocellulose of $66.79 \%$ and $95.26 \%$ in raw and pulp straw, respectively, besides the synthesis and characterization of the sec-butylammonium acetate, sec-butylammonium lactate, n-butylammonium acetate and n-butylammonium lactate. Afterward, the treatment of the raw and pulped straw was carried out with the ILs and subsequent enzymatic hydrolysis. A glucose mass ratio of up to $17.57 \%$ was verified in the pulp straw and treated with nbutylammonium acetate, against, 3.98\% in the only pulped straw and an increase of up to $90.7 \%$ in the mass ratio of fermentable sugars in the treated straw compared to the untreated straw. This efficiency is greater when using ionic liquids with the n-butylammonium cation.
\end{abstract}

KEYWORDS: Lignocellulosic residue; Biofuels; Ionic liquid; Enzymatic hydrolysis 